\title{
PRODUTIVIDADE DE CULTIVARES DE SOJA NO ANO AGRÍCOLA 2020/21 COM E SEM IRRIGAÇÃO SUPLEMENTAR EM TRÊS ÉPOCAS DE SEMEADURA NA REGIÃO CENTRAL DO RIO GRANDE DO SUL
}

TÍ PRODUCTIVITY OF SOYBEAN CULTIVARS IN THE 2020/21 AGRICULTURAL YEAR WITH AND WITHOUT SUPPLEMENTARY IRRIGATION IN THREE SEEDING SEASONS IN THE CENTRAL REGION OF RIO GRANDE DO SUL \&

PRODUCTIVIDAD DE LOS CULTIVARES DE SOJA EN EL AÑO AGRÍCOLA 2020/21 CON Y SIN RIEGO SUPLEMENTARIO EN TRES SEMILLAS EN LA REGIÓN CENTRAL DE RIO GRANDE DO SUL \&

Recebido em: 22/10/2021 - Aprovado em: 26/11/2021 - Publicado em: 17/12/2021

doi

http://dx.doi.org/10.18011/bioeng2021v15n4p561-576

Zanandra Boff de Oliveira ${ }^{1}$ (zanandraboff@gmail.com)

Alberto Eduardo Knies ${ }^{1}$ (albertoek@gmail.com)

\footnotetext{
1 Universidade Federal de Santa Maria. Cachoeira do Sul, RS, Brasil.

2 Universidade Estadual do Rio Grande do Sul. Cachoeira do Sul, RS, Brasil.
}

\section{RESUMO}

O presente estudo teve como objetivo avaliar a influência da irrigação suplementar e de três épocas de semeadura (5/11/20; 3/12/20 e 14/1/21) sobre a produtividade de cultivares de soja de distintos grupos de maturidade relativa GMRs $(5.0 ; 5.5 ; 6.3)$, semeadas em Argissolo Vermelho distrófico típico sob clima subtropical úmido característico da Região Central do Rio Grande do Sul, Brasil. A irrigação suplementar proporcionou incrementos positivos em todos os componentes de rendimento da soja, propiciando ganhos médios de produtividade em torno de $37 \%$, possibilitando atingir uma produtividade de até $6757,5 \mathrm{~kg} \mathrm{ha}^{-1}$ na semeadura de 5/11. As cultivares de GMR 5.5 e 6.3 foram mais produtivas independente do regime hídrico e para as três épocas de semeadura. Houve redução em todos os componentes de rendimento da soja e na produtividade em média de $32 \mathrm{~kg}$ ha dia-1 com o atraso da semeadura de 5/11 para 14/1.

Palavras-chave: Produtividade da soja. Suplementação Hídrica.Cultivares.

Artigo publicado sob a licença Creative Commons - Atribuição 4.0 Internacional (CC BY 4.0). 
1 INTRODUÇÃO

A soja é o principal grão oleaginoso cultivado no mundo. Seu elevado teor em proteínas faz dela a principal matéria prima na fabricação de rações para alimentação de animais domésticos, além de seu elevado potencial para a extração de óleo vegetal (DALL'AGNOL et al., 2007). Na safra 2020-21 foram cultivadas em torno de 38,502 milhões de hectares no Brasil com uma produtividade média de $3.517 \mathrm{~kg} \mathrm{ha}^{-1}$, totalizando 135,409 milhões de toneladas do grão, sendo o estado do Rio Grande do Sul responsável pela produção de 20,164 milhões de toneladas (CONAB, 2021).

O crescimento, desenvolvimento e, consequentemente, rendimento de grãos da soja resultam da interação entre a cultivar utilizada e os fatores do meio decorrentes da sensibilidade ao fotoperíodo e a temperatura do ar (MUNDSTOK; THOMAS, 2005). Para Zanon et al. (2015), fatores ambientais representam $80 \%$ da variação da produtividade na cultura da soja.

Segundo Bergamaschi et al. (2004), o déficit hídrico é o maior causador da redução na produção das culturas de primavera-verão no RS. O estado apresenta forte sinal do fenômeno El Niño Oscilação Sul (ENOS), sendo a principal causa da variabilidade climática (MONTECINOS et al., 2000; BERLATO et al., 2005). Esse fenômeno apresenta duas fases extremas: uma fase quente denominada El Niño (chuvas acima da normal climatológica) e uma fase fria denominada La Niña (chuvas abaixo da normal climatológica), especialmente na primavera-início de verão do ano de início do fenômeno (FONTANA; BERLATO, 1996; BERLATO; FONTANA, 2003; PUCHALSKI, 2000).

A necessidade hídrica da soja varia entre 450 a $850 \mathrm{~mm}$ dependendo do clima e da duração do ciclo de desenvolvimento da cultivar (DOORENBOS; KASSAN, 1994). A demanda por água aumenta progressivamente com o desenvolvimento da cultura da soja, atingindo o máximo no florescimento até o início da formação de legumes e se mantém alta até a maturação (THOMAS; COSTA, 2010), destacando-se dois períodos críticos com relação à falta de água: a fase inicial de estabelecimento da cultura e o enchimento dos grãos (FARIAS et al., 2001). Zanon et al. (2018), ressalta que para altas produtividades (acima de $5.000 \mathrm{~kg} \mathrm{ha}^{-1}$ ) são necessários aproximadamente $800 \mathrm{~mm}$ de água ao longo do ciclo da cultura.

Mesmo com os conhecidos prejuízos do déficit hídrico para a produtividade da soja no estado (DOORENBOS; KASSAN, 1994; SENTELHAS et al., 2015, ZANON et al., 2018), a maioria das áreas cultivadas com soja são no regime de sequeiro (SENTELHAS et al., 
2015). Assim, a irrigação suplementar é uma estratégia que pode aumentar significativamente a produtividade da soja (MONTOYA et al., 2017) e estabilizar a produção agrícola, especialmente durante anos de Lã Niña.

A época de semeadura é também uma importante prática de manejo para se conciliar condições adequadas de chuvas, temperatura, radiação solar e fotoperíodo, com estágios críticos da cultura, sem alterar significativamente os custos de cultivo (ZANON et al., 2018; MEOTTI et al., 2012). Assim como, o posicionamento de cultivares baseado em resultados de produtividade regionais (adaptabilidade da cultivar ao local) e em seu grupo de maturidade relativa (GMR). O GMR representa a duração do ciclo de desenvolvimento da soja (ALLIPRANDINI et al., 2009), são formas de minimizar os efeitos da variabilidade do clima na produtividade da soja.

Nesse sentido, o presente estudo teve como objetivo avaliar a influência da irrigação suplementar e de três épocas de semeadura (5 de nov.; 3 de dez. e 14 de jan.) na produtividade de cultivares de soja de distintos GMRs $(5.0 ; 5.5 ; 6.3)$, nas condições edafoclimáticas da Região central do RS.

\section{MATERIAIS E MÉTODOS}

No ano agrícola 2020-21 foi instalado um experimento de campo com a cultura da soja (Glycine max) em área experimental da Universidade Estadual do Rio Grande do Sul, localizada no distrito de Três Vendas no município de Cachoeira do Sul - RS (2953' S e $53^{\circ} 00^{\prime} \mathrm{W}$, altitude de $125 \mathrm{~m}$ ). O clima da região é classificado por Köppen (1931), como subtropical úmido, Cfa, predominante na região Sul. O solo da área experimental foi classificado como Argissolo Vermelho distrófico típico (EMBRAPA, 2013).

O experimento foi conduzido no esquema fatorial $(3 \times 3 \times 2)$ em quatro repetições. $O$ fator "E" constituiu de três épocas de semeadura da soja: 05 de novembro de 2020 (Época 1), 3 de dezembro (Época 2), 14 de janeiro de 2021 (Época 3). O fator "C" constitui de três cultivares de soja: BMX Raio IPRO (GMR 5.0), BMX Zeus IPRO (GMR 5.3) e BMX Garra IPRO (GMR 6.3) e o fator "H" de dois regimes hídricos: irrigado e não irrigado (sequeiro). A semeada foi realizada com um conjunto trator-semeadora, no sistema de plantio direto com espaçamento entrelinhas de cultivo de $0,50 \mathrm{~m}$, na densidade de semeadura de 300.000 planta ha-1. Os demais manejos e tratos culturais, seguiram as recomendações agronômicas para a cultura da soja. 
O sistema de irrigação utilizado foi a aspersão convencional, em que os aspersores (modelo Plona Pa 150 - 5 x 12 Mn) foram instalados no espaçamento de $6 \times 6$ m, com uma taxa de aplicação de $12 \mathrm{~mm} \mathrm{~h}^{-1}$. A cultura foi irrigada para manter o armazenamento de água do solo próximo a $60 \%$ da capacidade de água disponível (CAD) - umidade entre a capacidade de campo $\left(0,318 \mathrm{~cm}^{3} \mathrm{~cm}^{-3}\right)$ e o ponto de murcha permanente $\left(0,148 \mathrm{~cm}^{3} \mathrm{~cm}^{-3}\right)$, na camada de 0 a $60 \mathrm{~cm}$ de profundidade de perfil do solo. Tal fração de água disponível (CAD real, $\mathrm{mm}$ ) correspondeu a $36 \mathrm{~mm}$ de água armazenada. Para a aferição do armazenamento de água no solo (CAD atual real, $\mathrm{mm}$ ) medidas do conteúdo volumétrico de água no solo foram realizadas por meio de sensores FDR $(0-60 \mathrm{~cm})$, nas parcelas irrigadas.

Para o cálculo do balanço hídrico, as chuvas e as irrigações foram as entradas de água no sistema, sendo que quando a chuva foi maior que a CAD real, o valor excedente não foi considerado como chuva efetiva, contabilizando como perdas por escoamento superficial e percolação. A evapotranspiração da cultura (ETc) foi a saída de água do sistema e sua estimativa baseou-se na proposta por ALLEN et al. (1998). Os dados meteorológicos necessários para o cálculo da evapotranspiração de referência (ETo) foram obtidos de uma estação meteorológica automática situada próxima ao local do experimento, administrada pelo Irriga Global, que disponibilizou esses dados. Para o ajuste da curva do Kc (simples) utilizou-se a metodologia proposta por ALLEN et al. (1998) com a fração de cobertura do dossel (Fc). A Fc foi estimada por meio de uma grade quadriculada de 0,50 $\mathrm{x}$ $0,50 \mathrm{~m}$ com malha de $0,10 \times 0,10 \mathrm{~cm}$, em que se obteve a cobertura do dossel em relação ao máximo que pode ocupar para aquele espaçamento entrelinha e entre plantas. Realizouse também, avaliações fenológicas para o acompanhamento do ciclo de desenvolvimento da cultura.

Com os dados de temperatura média do ar foi calculado o somatório térmico acumulado (ST) $\mathrm{STac}=\sum \mathrm{STd}$, a partir da soma térmica diária (STd) conforme a Equação 1, determinada pela diferença entre a temperatura média (Tméd) do i-ésimo dia do ciclo e a temperatura de base da cultura $\left(\mathrm{Tb}=10^{\circ} \mathrm{C}\right)$.

$$
S T d=\text { Tméd }-T b
$$


Figura 1. Soma térmica acumuladas durante o ciclo de desenvolvimento da soja da semeadura a colheita (ST ac.) e da semeadura a floração (R1).

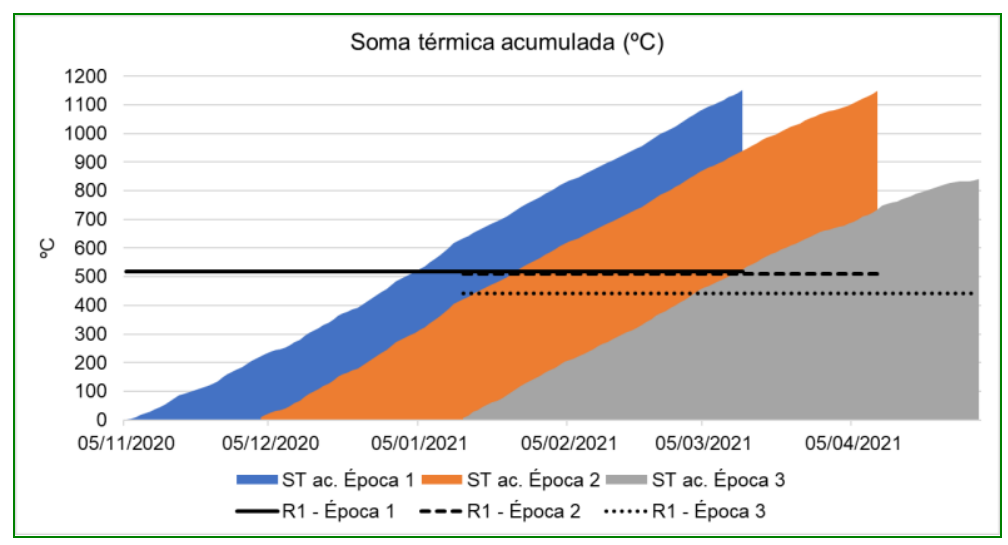

Fonte: Autor, 2021

Para a análise da produtividade, realizou-se a colheita manual das plantas da área central de cada parcela experimental $\left(3 \mathrm{~m}^{2}\right)$ e procedeu-se a contagem das plantas, a trilha, a limpeza, a determinação da umidade dos grãos e a pesagem. O peso obtido foi corrigido para uma umidade de $13 \%$ e extrapolado para hectare $\left(\mathrm{kg} \mathrm{ha}^{-1}\right)$ baseado na população de 300.000 plantas ha-1. Para a análise dos componentes do rendimento: número de vagens por planta, número de grãos por vagem, peso de mil grãos (PMG) (g), foram selecionadas aleatoriamente quatro plantas por parcela, que foram processadas manualmente. Para a determinação do PMG mediu-se a umidade e o peso obtido foi corrigido para uma umidade de $13 \%$

As variáveis repostas obtidas foram submetidas a análise da variância pelo teste $F$ e análise complementar: teste "Tukey" (fatore cultivar e regime hídrico) e análise de regressão (fator época de semeadura), em nível de 5\% de probabilidade de erro.

\section{RESULTADOS E DISCUSSÃO}

As chuvas acumuladas durante o ciclo de desenvolvimento da cultura da soja somaram 426, 436 e 325 mm superando a evapotranspiração acumulada da cultura que foi de 403, 384 e 284 mm, para as épocas de semeadura 1, 2 e 3, respectivamente. A redução nos valores de evapotranspiração acumulada com o atraso da época de semeadura, é atribuída a redução na duração do ciclo de desenvolvimento da cultura (Figuras 1 e 2) e a redução da demanda da atmosfera no período de maior consumo hídrico da soja. A duração 
das fases e do ciclo de desenvolvimento da soja é regulada pela temperatura e fotoperíodo (KANTOLIC, 2008; ZANON, 2015).

Contudo, mesmo as chuvas acumuladas sendo maiores que a demanda da cultura, a distribuição irregular destas durante o ciclo de desenvolvimento, associada a alta demanda evapotranspirométrica da cultura na fase reprodutiva, superior a $7 \mathrm{~mm} \mathrm{dia}^{-1}$, resultaram na demanda por irrigações suplementares para manter o armazenamento de água no solo em níveis desejados, tais irrigações acumuladas no ciclo totalizaram $168 \mathrm{~mm}$ (Época 1), 164 mm (Época 2) e 143 mm (Época 3) (Figura 2).

Figura 2. Balanço hídrico da soja irrigada em três épocas de semeadura. Cachoeira do Sul, 2021.

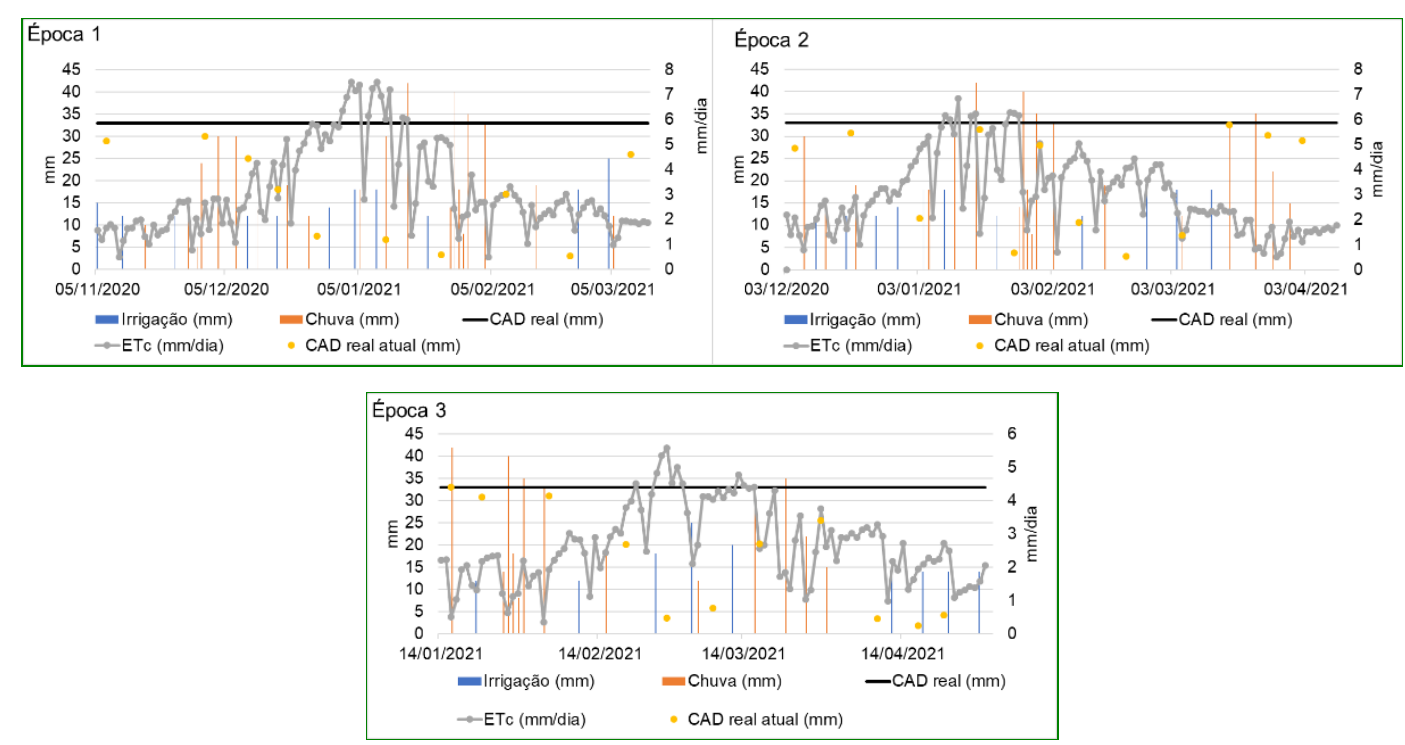

Observa-se na Figura 2 que para a fase inicial de estabelecimento da cultura, que é um dos períodos críticos ao déficit hídrico (FARIAS et al., 2001), houve uma maior necessidade de irrigação suplementar na primeira época de semeadura.

$\mathrm{Na}$ fase reprodutiva, em que o déficit hídrico é extremamente prejudicial, pois provoca impactos negativos diretos nos componentes de rendimento da soja, a demanda por irrigação suplementar acorreu para todas as épocas de semeadura estudadas. De acordo com Gajić et al. (2018), na fase reprodutiva da cultura da soja é importante que não ocorra nenhum déficit hídrico, uma vez que esta é a fase em que serão definidos os componentes de produtividade.

Na Tabela 1 é possível observar que houve diferença significativa $(P<0,05)$ entre as épocas de semeadura $(E)$, as cultivares $(C)$ e os regimes hídricos $(H)$ em relação à todas 
as variáveis respostas. Não houve diferença significativa para o efeito da interação entre $E$ x C x H sobre as variáveis resposta. Houve diferença significativa para o efeito da interação $\mathrm{C} \times \mathrm{H}$ sobre as variáveis resposta, indicando que o efeito do regime hídrico é dependente das cultivares e vice-versa, cujos resultados estão apresentados na tabela 2.

Tabela 1. Resumo da análise da variância para as variáveis respostas. Cachoeira do Sul, 2021.

\begin{tabular}{ccccc}
\hline \multicolumn{5}{c}{ Valor do F calculado } \\
\hline Fontes de Variação & Vagem por planta & Grãos por vagem & PMG & Produtividade \\
\hline E & $2,72^{*}$ & $10,10^{*}$ & $20,67^{*}$ & $16,67^{*}$ \\
\hline C & $2,59^{*}$ & $19,24^{*}$ & $8,17^{*}$ & $3,07^{*}$ \\
\hline H & $23,1^{*}$ & $11,44^{*}$ & $43,90^{*}$ & $36,37^{*}$ \\
\hline E X C & $0,71^{\mathrm{ns}}$ & $0,03^{\mathrm{ns}}$ & $1,80^{\mathrm{ns}}$ & $0,74^{\mathrm{ns}}$ \\
\hline E X H & $1,64^{\mathrm{ns}}$ & $0,84^{\mathrm{ns}}$ & $5,16^{\mathrm{ns}}$ & $0,69^{\mathrm{ns}}$ \\
\hline C xH & $0,27^{*}$ & $1,75^{*}$ & $4,22^{*}$ & $0,18^{*}$ \\
\hline EXC X H & $0,14^{\mathrm{ns}}$ & $1,30^{\mathrm{ns}}$ & $1,77^{\mathrm{ns}}$ & $0,22^{\text {ns }}$ \\
\hline CV (\%) & 28,2 & 7,14 & 5,6 & 32,9 \\
\hline época de semeadura; C: cultivar; H: regime hídrico; PMG: peso de mil grãos; CV: coeficiente de \\
variação; * Pr>Fc ser igual ou menor que 0,05; ns: Pr>Fc ser maior que 0,05.
\end{tabular}

Fonte: Autor, 2021.

A irrigação suplementar proporcionou um incremento médio de 17 vagens por planta, sendo o maior incremento de 21 vagem por planta para a cultivar de GMR 5.5. O número de grãos por vagem, foi aumentado em 0,2 para as cultivares de GMR 5.0 e 6.3 e o PMG foi em média $18 \mathrm{~g}$ superior com a utilização da irrigação, que proporcionou maior incremento (28 g) para a cultivar de GMR 5.0. Assim, a irrigação suplementar proporcionou um incremento médio de produtividade da soja de $37 \%$. Sendo que, as cultivares de GMR 5.5 e 6.3 foram as mais produtivas em ambos os regimes hídricos (Tabela 2) e para as três épocas de semeadura avaliadas (Tabela 3 ).

Para as épocas de semeadura 1 e 2 a cultivar de GMR 6.3 apresentou maior número de vagem por planta. Já, para a Época 3 todas as cultivares obtiveram valores semelhantes para esse componente de rendimento. O número de grãos por vagem foi maior para a cultivar de GMR $5.5 \mathrm{em}$ todas as épocas de semeadura. Diferenças no PMG entre as cultivares aconteceram penas na primeira época de semeadura em que as cultivares mais precoces (GMR 5.5 e 5.0) apresentaram valores maiores (Tabela 3), por possivelmente já terem passado por esta etapa do ciclo no momento da ocorrência da redução das chuvas (Figura 2). 
Tabela 2. Resultado dos componentes de rendimento e da produtividade da soja paras as três cultivares avaliadas com e sem irrigação. Cachoeira do Sul, 2021.

\begin{tabular}{|c|c|c|c|}
\hline \multirow[b]{2}{*}{ Regime Hídrico } & \multicolumn{3}{|c|}{ Cultivares } \\
\hline & GMR 5.0 & GMR 5.5 & GMR 6.3 \\
\hline & \multicolumn{3}{|c|}{ Vagem por planta } \\
\hline Irrigado & $56,3 \mathrm{Ba}$ & $62,1 \mathrm{ABa}$ & $67,9 \mathrm{Aa}$ \\
\hline \multirow[t]{2}{*}{ Não irrigado } & $42,2 \mathrm{Ab}$ & $41,3 \mathrm{Ab}$ & $51,3 \mathrm{Ab}$ \\
\hline & \multicolumn{3}{|c|}{ Grãos por vagem } \\
\hline Irrigado & $2,1 \mathrm{ABa}$ & $2,3 \mathrm{Aa}$ & $2,2 \mathrm{ABa}$ \\
\hline \multirow[t]{2}{*}{ Não irrigado } & $2,0 \mathrm{Bb}$ & $2,3 \mathrm{Aa}$ & $2,0 \mathrm{Bb}$ \\
\hline & \multicolumn{3}{|c|}{ PMG (g) } \\
\hline Irrigado & $211,2 \mathrm{ABa}$ & $217,1 \mathrm{Aa}$ & $201,6 \mathrm{Ba}$ \\
\hline \multirow[t]{2}{*}{ Não irrigado } & $182,3 \mathrm{Bb}$ & $200,4 \mathrm{Ab}$ & $193,0 \mathrm{ABb}$ \\
\hline & \multicolumn{3}{|c|}{ Produtividade $\left(\mathrm{kg} \mathrm{ha}^{-1}\right)$} \\
\hline Irrigado & $4597,5 \mathrm{Ba}$ & $5752,5 \mathrm{Aa}$ & $5452,5 \mathrm{Aa}$ \\
\hline Não irrigado & $2782,5 \mathrm{Bb}$ & $3472,5 \mathrm{Ab}$ & $3667,5 \mathrm{Ab}$ \\
\hline
\end{tabular}

Valores médios seguidos de letras maiúsculas iguais nas colunas e de letras minúsculas iguais nas linhas não diferem entre si em nível de $5 \%$ de probabilidade de erro conforme teste de Tukey.

Fonte: Autor, 2021.

Tabela 3. Resultado dos componentes de rendimento e da produtividade da soja para as três cultivares avaliadas nas três épocas de semeadura. Cachoeira do Sul, 2021.

\begin{tabular}{lcccccc}
\hline & \multicolumn{5}{c}{ Cultivares } \\
\hline \multirow{2}{*}{ Época de semeadura } & GMR 5.0 & GMR 5.5 & GMR 6.3 \\
\cline { 2 - 7 } & \multicolumn{5}{c}{ Vagem por planta } \\
\hline Época 1 & 53,8 & C & 63,4 & B & 73,8 & A \\
\hline Época 2 & 50,4 & B & 49,8 & B & 58,6 & A \\
\hline Época 3 & 43,6 & A & 42,0 & A & 46,5 & A \\
\hline \multicolumn{5}{c}{ Grãos por vagem } \\
\hline Época 1 & 2,1 & B & 2,4 & A & 2,2 & B \\
\hline Época 2 & 2,1 & B & 2,4 & A & 2,2 & B \\
\hline Época 3 & 2,0 & B & 2,2 & A & 2,0 & B \\
\hline \multicolumn{5}{c}{} & \multicolumn{5}{c}{ PMG (g) } \\
\hline Época 1 & 211,6 & AB & 222,1 & A & 201,6 & B \\
\hline Época 2 & 196,1 & A & 209,2 & A & 197,3 & A \\
\hline Época 3 & 184,7 & A & 194,9 & A & 192,9 & A \\
\hline \multicolumn{5}{c}{ Produtividade (kg ha-1) } \\
\hline Época 1 & 4342,5 & B & 6142,5 & A & 5962,5 & A \\
\hline Época 2 & 3802,5 & B & 4432,5 & A & 4477,5 & A \\
\hline Época 3 & 2925,0 & B & 3262,5 & A & 3240,0 & A \\
\hline
\end{tabular}

Valores médios seguidos de letras maiúsculas iguais nas colunas não diferem entre si em nível de $5 \%$ de probabilidade de erro conforme teste de Tukey.

Fonte: Autor, 2021. 
Para a Época 1, a ocorrência de irrigações suplementares (Figura 2) foi maior no período de floração e plena floração, em que se define o número de vagens por planta, essa maior disponibilidade hídrica proporcionou um incremento de 25 vagem por planta (Tabela 4). Na Época 2 a demanda por irrigação (Figura 2) foi maior no período de enchimento de grãos, impactando em maiores diferenças no PMG que foi $28 \mathrm{~g}$ maior na soja irrigada para essa época (Tabela 4). Na Época 3 foi no período de floração e no período final de enchimento de grãos (Figura 2). Déficits hídricos expressivos, durante a floração e o enchimento de grãos, provocam alterações fisiológicas na planta, como o fechamento estomático e o murchamento de folhas e, como consequência, aumentam a queda prematura de flores e ocasionam o abortamento de vagens (FARIAS et al., 2020, STRECK, 2004; TAIZ; ZAIGER, 2013).

Tabela 4. Resultado dos componentes de rendimento e da produtividade da soja para o regime hídrico irrigado e não irrigado nas três épocas de semeadura. Cachoeira do Sul, 2021.

\begin{tabular}{|c|c|c|}
\hline \multirow{3}{*}{$\begin{array}{l}\text { Época de } \\
\text { semeadura }\end{array}$} & \multicolumn{2}{|c|}{ Regime Hídrico } \\
\hline & Irrigado & Não irrigado \\
\hline & \multicolumn{2}{|c|}{ Vagem planta ${ }^{-1}$} \\
\hline Época 1 & $76,2 \quad A$ & $51,1 \quad \mathrm{~B}$ \\
\hline Época 2 & 58,3 A & $47,5 \quad \mathrm{~B}$ \\
\hline \multirow[t]{2}{*}{ Época 3} & $51,8 \quad A$ & $36,3 \quad \mathrm{~B}$ \\
\hline & \multicolumn{2}{|c|}{ Grãos vagem ${ }^{-1}$} \\
\hline Época 1 & $2,3 \mathrm{~A}$ & $2,2 \mathrm{~B}$ \\
\hline Época 2 & $2,3 \mathrm{~A}$ & $2,2 \mathrm{~B}$ \\
\hline \multirow[t]{2}{*}{ Época 3} & $2,1 \quad \mathrm{~A}$ & $2,0 \quad B$ \\
\hline & \multicolumn{2}{|c|}{ PMG (g) } \\
\hline Época 1 & $215,3 \quad A$ & $208,3 \quad B$ \\
\hline Época 2 & $214,9 \quad \mathrm{~A}$ & $186,9 \quad \mathrm{~B}$ \\
\hline \multirow[t]{2}{*}{ Época 3} & 199,8 A & $181,9 \mathrm{~B}$ \\
\hline & \multicolumn{2}{|c|}{ Produtividade (kg ha-1) } \\
\hline Época 1 & $6757,5 \mathrm{~A}$ & $4207,5 \quad \mathrm{~B}$ \\
\hline Época 2 & $5055,0 \mathrm{~A}$ & $3420,0 \quad B$ \\
\hline Época 3 & $3990,0 \mathrm{~A}$ & $2295,0 \quad B$ \\
\hline
\end{tabular}

Valores médios seguidos de letras maiúsculas iguais nas colunas não diferem entre si em nível de $5 \%$ de probabilidade de erro conforme teste de Tukey.

Fonte: Autor, 2021.

A irrigação suplementar proporcionou incrementos positivos em todos os componentes de rendimento, resultando em ganhos médios de produtividade em torno de $37 \%$, sendo possível atingir a produtividade máxima de $6757,5 \mathrm{~kg}^{-1}{ }^{-1}$ na primeira época 
de semeadura (Tabela 4). Corroborando com Battisti et al. (2018) que a irrigação suplementar da soja no Rio Grande do Sul é uma prática imprescindível para a constância e a busca de altos níveis de produtividade

Na Figura 3 é possível observar que na medida em que ocorre o atraso na época de semeadura há uma a redução linear em todos os componentes de rendimento e na produtividade da soja, cujas as equações de regressão significativas $(P<0,05)$ estão apresentadas na Tabela 5.

Figura 3. Resultado dos componentes de produtividade: e da produtividade da soja em função da época da semeadura. Sendo que a linha cheia representa valores observados e a linha pontilhada representa valores ajustados pela equação regressão. Cachoeira do Sul, 2021.

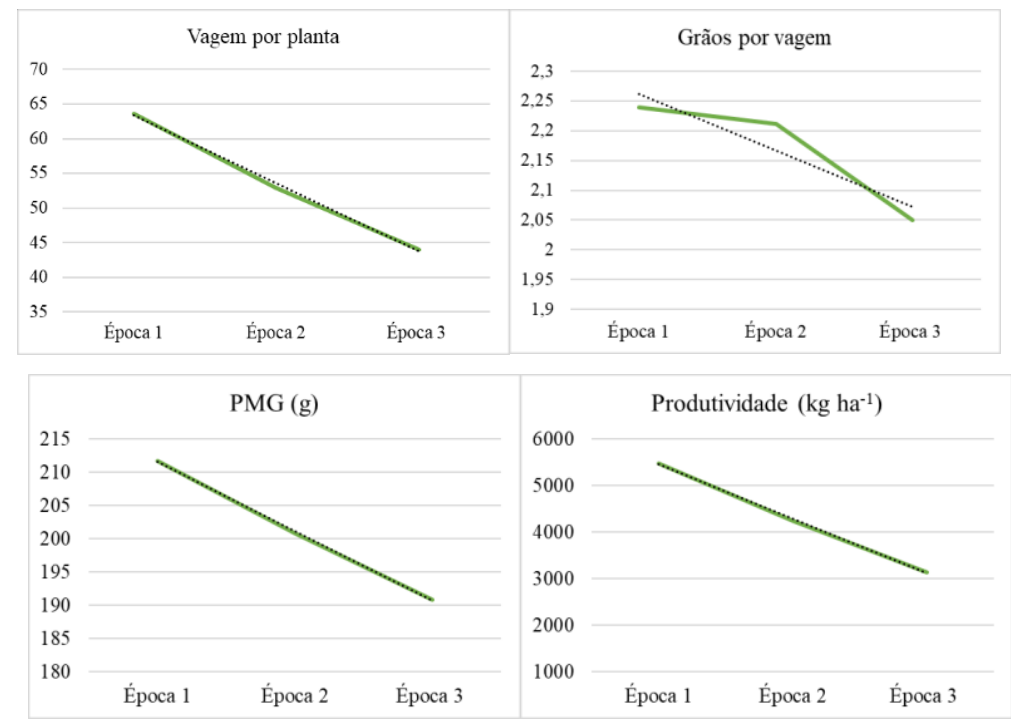

Fonte: Autor, 2021.

Tabela 5. Equações de regressão ajustadas para cada variável resposta analisada. Cachoeira do Sul, 2021.

\begin{tabular}{lcc}
\hline \multicolumn{1}{c}{ Variável resposta } & Equação & $\mathbf{R}^{\mathbf{2}}$ \\
\hline Vagem por planta & $y=-0,272034 * x+62,136046$ & 95,24 \\
\hline Grãos por vagem & $y=-0,002775 * x+2,253785$ & 95,36 \\
\hline PMG $(\mathrm{g})$ & $y=-0,292927 * x+210,6385$ & 97,62 \\
\hline Produtividade $\left(\mathrm{kg} \mathrm{ha}^{-1}\right)$ & $y=-32,567537 x+5920,516849$ & 96,14 \\
\hline
\end{tabular}

y: variável resposta; $x$ : variável dependente (data de semeadura devendo ser considerado valores entre 0 para a primeira época e 70 para última época); R2: coeficiente de determinação.

Fonte: Autor, 2021 
A produtividade da soja é reduzida em média de $32 \mathrm{~kg}$ ha dia-1 na medida em que ocorre o atraso da semeadura de 5 de novembro para 14 de janeiro (Figura 3 e Tabela 5). Sendo que, essa redução é de $38 \mathrm{~kg}$ ha dia-1 para a soja irrigada e de $26 \mathrm{~kg}^{-1}$ ha dia-1 para a soja de sequeiro (Tabela 4). Zanon et al. (2016) em estudos realizados no Rio Grande do Sul menciona que a cada dia de atraso da semeadura a partir de 4 de novembro perde-se $26 \mathrm{~kg}$ ha dia $^{-1}$ de produtividade em plantas de soja sem limitação de água.

Essa redução nos componentes de rendimento e na produtividade da soja em semeaduras tardias pode ser atribuída a outros fatores ambientais, que não é a disponibilidade hídrica, como a redução do fotoperíodo e da disponibilidade de radiação solar que acontece nessa região a partir de janeiro. No Rio Grande do Sul, durante a estação de cultivo da soja, a intensidade de radiação solar, o fotoperíodos e a temperatura do ar aumentam nos meses de setembro a dezembro, e diminuem nos meses de janeiro a abril (ZANON, 2015). A disponibilidade de radiação solar para a cultura da soja, está relacionada com a fotossíntese, elongação da haste principal e ramificações, expansão foliar, pegamento de vagens e grãos e fixação biológica (CÂMARA, 2000).

Os resultados apresentados demonstram a importância da semeadura na época recomendada, sendo possível atingir altas produtividades para a cultura, mesmo em uma condição de sequeiro, pela combinação de uma melhor hídrica durante o ciclo de desenvolvimento da cultura e o fato de período de floração e enchimento de grãos coincidir com a maior disponibilidade de radiação solar na região.

\section{CONCLUSÕES}

O ano agrícola 2020/21 caracterizou-se na região central do Rio Grande do Sul por apresentar uma quantidade de chuvas acumuladas durante o ciclo da cultura da soja superior a evapotranspiração da cultura para todas as épocas de semeadura avaliadas, ainda assim, demandando irrigações suplementares para manter o armazenamento de água no solo em níveis desejáveis.

A irrigação suplementar proporcionou incrementos positivos em todos os componentes de rendimento da soja, propiciando ganhos médios de produtividade em torno de $37 \%$, sendo possível atingir a produtividade de $6757,5 \mathrm{~kg} \mathrm{ha}^{-1}$ na primeira época de semeadura (5 de nov.). 
As cultivares de GMR 5.5 e 6.3 foram mais produtivas que a cultivar de GMR 5.0 tanto para a condição hídrica avaliada (com e sem irrigação) como para as três épocas de semeadura (5 de nov.; 3 de dez. e 14 de jan.)

Houve redução em todos os componentes de rendimento da soja e na produtividade em média de $32 \mathrm{~kg} \mathrm{ha}$ dia $^{-1}$ com o atraso da semeadura de 5 de novembro para 14 de janeiro.

\section{REFERÊNCIAS}

ALLEN, R. G.; PEREIRA, L.S.; RAES, D.; SMITH, M. Crop evapotranspiration Guidelines for computing crop water requirements. Roma: FAO, 1998, 300p. (Irrigation and Drainage Paper, 56). Disponível em: <http://www.fao.org/docrep/X0490E/X0490E00.htm>. Acesso em: 06 jun. 2021.

ALLIPRANDINI, L. F.; ABATTI, C.; BERTAGNOLLI, P. F.; CAVASSIM, J. E.; GABE, H. L.; KUREK, A.; MATSUMOTO, M. N.; OLIVEIRA, M. A. R. de; PITOL, C.; PRADO, L. C.; STECKLING, C. Understanding soybean maturity groups in brazil: environment, cultivar classification and stability. Crop Science, Madison, v.49, mai-jun, p.801-808, 2009.

BATTISTI, R. et al. Assessment of crop-management strategies to improve soybean resilience to climate change in Southern Brazil. Crop \& Pasture Science, v. 69, 2018.

BERGAMASCHI, H.; DALMAGO, G.A.; BERGONCI, J.I.; BIANCHI, C.A.M.; MÜLLER, A.G.; COMIRAN, F.; HECKLER, B.M.M. Distribuição hídrica no período crítico do milho e produção de grãos. Pesquisa Agropecuária Brasileira, v.39, p.831-839, 2004.

BERLATO, M.A.; FARENZENA, H.; FONTANA, D.C. Associação entre El Niño Oscilação Sul e a produtividade do milho no Estado do Rio Grande do Sul. Pesquisa Agropecuária Brasileira, v.40, p.423-432, 2005.

BERLATO, M.A.; FONTANA, D.C. El Niño e La Niña: impactos no clima, na vegetação e na agricultura do Rio Grande do Sul; aplicações de previsões climáticas na agricultura. Porto Alegre: UFRGS, 110p, 2003

CÂMARA, G.M.S. Soja: tecnologia da produção II. Gil Miguel de Sousa Câmara (editor). Piracicaba: G.M.S. Câmara, 2000. 450p.

CONAB. Boletim de Monitoramento Agrícola N. 5 - V. 10, 2021. Disponível in: https://www.conab.gov.br/info-agro/safras/graos/boletim-da-safra-de-graos. Acesso em: 06 set. 2021.

DALL'AGNOL, A.; ROESSING, A. C.; LAZZAROTTO, J. J.; HIRAKURI, M. H.; OLIVEIRA, A. B. O complexo agroindustrial da soja brasileira. Londrina: Embrapa Soja, 2007. 12 p. (Circular Técnica, 43) 
DOOREMBOS, J.; KASSAM, A. H. Efectos del água em rendimento de los cultivos. Campina Grande: UFPB, 1994. (FAO, Estudos de irrigação e drenagem, 33).

EMPRESA BRASILEIRA DE PESQUISA AGROPECUÁRIA - EMBRAPA. Sistema brasileiro de classificação de solos. Brasília, Editora:Embrapa, 3ed., p.353, 2013.

FARIAS, J. R. B.; ASSAD, E.D.; ALMEIDA, I.R.; EVANGELISTA, B.A.; LAZZAROTTO, C.; NEUMAIR, N.; NEPOMUCENO, A.L. Caracterização de Risco de Déficit Hídrico nas Regiões Produtoras de Soja no Brasil. Revista Brasileira de Agrometeorologia,, v.9, n.3, (№ Especial: Zoneamento Agrícola), p.415-421, 2001.

FARIAS, J.R.B.; NEUMAIER, N.; NEPOMUCENO, A. L. Árvore do conhecimento soja. EMBRAPA. Disponível in:

https://www.agencia.cnptia.embrapa.br/gestor/soja/arvore/CONT000fzr67crj02wx5ok0cpo o6aietiwl0.htm|\#: :text=A\%20necessidade\%20total\%20de\%20\%C3\%A1gua,da\%20dura\% C3\%A7\%C3\%A30\%20do\%20seu\%20ciclo. Acesso em: 02 set. 2020.

FONTANA, D.C.; BERLATO, M. A. Influência do El Niño Oscilação Sul (ENOS) sobre a precipitação do Estado do Rio Grande do Sul. Revista Brasileira de Agrometeorologia, v.5, p.127-132, 1997.

GAJIĆ, B.; KRESOVIC, B.; TAPANAROVA, A.; ZIVOTIC, L.; TODOROVIC, M. Effect of irrigation regime on yield, harvest index and water productivity of soybean grown under different precipitation conditions in a temperate environment. Agricultural Water Management, Elsevier, v. 210 (c), p. 224-23, 2018.

KANTOLIC, A. G. Control ambiental y genético de la fenologia del cultivo de soja: impactos sobre elrendimiento y laadaptación de genótipos. Revista da Facultad de Agronomía UBA, v. 28, p. 63-88, 2008.

KOEPPEN, W. Grundriss der Klimakunde. Berlin: Walter de Gruyter, 1931. 288 p.

MEOTTI, G. V., BENIN, G., SILVA, R. R., BECHE, E.; MUNARO, L. B. Épocas de semeadura e desempenho agronômico de cultivares de soja. Pesquisa agropecuária brasileira, Brasília, v.47, n.1, p.14-21, jan. 2012.

MONTECINOS, A,; DÍAZ, A.; ACEITUNO, P. Seasonal diagnostic and predictability of rainfall in subtropical South America based on Tropical Pacific SST. Journal of Climate, Boston, v.13, p.746-758, 2000.

MONTOYA, F. C.; PINTOS, F.; OTERO, A. Effects of irrigation regime on the growth and yield of irrigated soybean in temperate humid climatic conditions. Agricultural Water Management, Elsevier, v.193, p.30-45, 2017.

MUNDSTOCK, C.M.; THOMAS, A.L. Soja: fatores que afetam o crescimento e rendimento de grãos. Porto Alegre: Universidade Federal do Rio Grande do Sul, 2005. $31 \mathrm{p}$. 
PUCHALSKI, L. A. Efeitos associados ao El Niño e La Niña na temperatura média, precipitação pluvial e o déficit hídrico no estado do Rio Grande do Sul. Porto Alegre, 2000. 83f. Dissertação (Mestrado em Fitotecnia, área de concentração em Agrometeorologia) Faculdade de Agronomia, Universidade Federal do Rio Grande do Sul.

SENTELHAS, P. C; BATTISTI, R.; CÂMARA, G.M.S; FARIAS, J.R.B.; HAMPF, A.C.; NENDEL, C. The Soybean Yield Gap in Brazil - Magnitude, Causes and Possible Solutions for a Sustainable Production. Journal of Agriculture Science, Cambridge, v. 153, p. 1394-1411, 2015.

STRECK, N.A. Do we know how plants sense a drying soil?. Ciência Rural. Santa Maria,v. 34, p.581-584. 2004.

ZANON, A. J. Growth, development and soybean yield potential as a function of growing type and maturity group in subtropical environment. 2015. $179 \mathrm{f}$. Tese (Doutorado em Agronomia) - Universidade Federal de Santa Maria, Santa Maria, 2015.

ZANON, A. J.; SILVA, M. R., TAGLIAPIETRA, E.L.; CERA, J.C Ecofisiologia da sojaVisando altas produtividades. $1^{\circ}$ ed. Santa Maria: [n.s.], 2018. ISBN: 978-85-54856-144. $136 p$.

ZANON, A. J.; STRECK, N.A.; GRASSINI, P. Climate and management factors influence soybean yield potential in a subtropical environment. Agronomy Journal, v. 108, p.14471454, 2016. 


\begin{abstract}
The present study aimed to evaluate the influence of supplementary irrigation and three sowing times $(5 / 11 / 20 ; 3 / 12 / 20$ and $14 / 1 / 21)$ on the yield of soybean cultivars from different groups of relative maturity GMRs $(5.0 ; 5.5 ; 6.3)$, sown in a typical dystrophic Red Ultisol under humid subtropical climate characteristic of the Central Region of Rio Grande do Sul, Brazil. Supplemental irrigation provided positive increments in all soybean yield components, providing average yield gains of around $37 \%$, making it possible to reach a yield of up to $6757.5 \mathrm{~kg} \mathrm{ha}^{-1}$ in the $5 / 11$ sowing. Cultivars of GMR 5.5 and 6.3 were more productive regardless of the water regime and for the three sowing dates. There was a reduction in all soybean yield components and in productivity by an average of $32 \mathrm{~kg}$ ha day${ }^{1}$ with the delay in sowing from $5 / 11$ to $14 / 1$.
\end{abstract}

Keywords: Soybean productivity. Water Supplementation. Cultivars.

\title{
RESUMEN
}

El presente estudio tuvo como objetivo evaluar la influencia del riego suplementario y tres tiempos de siembra (5/11/20; 3/12/20 y 14/1/21) sobre el rendimiento de cultivares de soja de diferentes grupos de GMR de madurez relativa (5.0; 5.5; 6.3), sembrado en un típico Ultisol Rojo distrófico bajo el clima subtropical húmedo característico de la Región Central de Rio Grande do Sul, Brasil. El riego suplementario proporcionó incrementos positivos en todos los componentes del rendimiento de la soja, proporcionando ganancias de rendimiento promedio de alrededor del $37 \%$, lo que permitió alcanzar un rendimiento de hasta $6757,5 \mathrm{~kg} \mathrm{ha}^{-1}$ en la siembra del 5/11. Los cultivares de GMR 5.5 y 6.3 fueron más productivos independientemente del régimen hídrico y para las tres fechas de siembra. Hubo una reducción en todos los componentes del rendimiento de la soja y en la productividad en un promedio de $32 \mathrm{~kg}$ ha día ${ }^{-1}$ con el retraso en la siembra del 5/11 al 14/1.

Palabras-clave: Productividad de la soja. Suplementación de agua. Cultivares. 


\section{LICENÇA DE USO}

Este é um artigo publicado em acesso aberto (Open Access) sob a licença Creative Commons Atribuição 4.0 Internacional (CC BY 4.0), que permite uso, distribuição e reprodução em qualquer meio, desde que o trabalho original seja corretamente citado. Mais informações em: http://creativecommons.org/licenses/by/4.0

\section{CONFLITO DE INTERESSES}

Os autores declaram que não há conflito de interesses neste trabalho.

\section{CONTRIBUIÇÕES AUTORAIS}

Autor 1: Autor principal.

Autor 2: Co-autor do trabalho.

\section{FINANCIAMENTO}

O presente trabalho não contou com apoio financeiro.

\section{COMO REFERENCIAR}

OLIVEIRA, Zanandra Boff de; KNIES, Alberto Eduardo. Produtividade de cultivares de soja no ano agrícola 2020/21 com e sem irrigação suplementar em três épocas de semeadura na região central do RS. Revista Brasileira de Engenharia de Biossistemas (Tupã), v. 15, n. 4, p. 561-576, 2021. DOI:

http://dx.doi.org/10.18011/bioeng2021v15n4p561-576.

\section{RESPONSABILIBADE EDITORIAL}

Prof. Dr. Fernando Ferrari Putti ${ }^{1}$, Prof. Dr. Paulo Sérgio Barbosa dos Santos ${ }^{1}$, Prof. Dr. Eduardo Festozo Vicente ${ }^{1}$ e Prof. Dr. Diogo de Lucca Sartori ${ }^{1}$

1 Universidade Estadual Paulista "Júlio de Mesquita Filho", FCE - Faculdade de Ciências e Engenharia, Tupã, SP, Brasil. 